Check for updates

Cite this: Chem. Commun., 2019, 55,7832

Received 14th March 2019,

Accepted 11th June 2019

DOI: $10.1039 /$ c9cc02088h

rsc.li/chemcomm

\section{Evidence for tetranuclear bis- $\mu$-oxo cubane species in molecular iridium-based water oxidation catalysts from XAS analysis $\dagger$}

\author{
Stuart A. Bartlett, (D) *a Emma V. Sackville, ${ }^{b}$ Emma K. Gibson, (D) ac \\ Veronica Celorrio, (D) a Peter P. Wells, (D) ad Maarten Nachtegaal, ${ }^{e}$ \\ Stafford W. Sheehan (D) ${ }^{f}$ and Ulrich Hintermair (D) $*^{b}$
}

The structure of a highly active pyridine-alkoxide iridium water oxidation catalyst (WOC) is examined by X-ray absorption spectroscopy (XAS). A detailed comparison with $\mathrm{IrO}_{2}$ points to a rigid molecular unit of low nuclearity, with the best analysis suggesting a novel tetrameric iridium-oxo cubane as the resting state.

The water oxidation reaction continues to present a major challenge for the efficient transformation of renewable electricity into chemical energy. ${ }^{1,2}$ Although a number of well-defined molecular precursors to highly active water oxidation catalysts (WOCs) have been developed, ${ }^{3,4}$ there still is a distinct lack of structural and electronic insight into their reaction intermediates. This often hampers the rational development toward improved systems that meet the robustness and stability requirements for practical applications. To date, commercial electrolysers thus exclusively employ heterogeneous metal oxide anodes, with amorphous iridium oxy-hydroxide still standing as the most active and durable WOC material known. ${ }^{5}$ A number of recent X-ray absorption spectroscopy (XAS), X-ray photoelectron spectroscopy (XPS), UV-vis spectroscopy, and electrochemistry studies of $\mathrm{IrO}_{x}$ surfaces under working conditions consistently suggest $\mathrm{Ir}^{\mathrm{III}}-\mathrm{Ir}^{\mathrm{IV}}-\mathrm{Ir}^{\mathrm{V}}$ redox cycles across two neighboring metal sites to effect the four-electron oxidation of water to $\mathrm{O}_{2} \cdot{ }^{6-11}$

The geometry of rutile $\mathrm{IrO}_{2}$ suggests this to be possible through a "diamond core" bis- $\mu$-oxo unit, a structural feature that is also found in many other WOCs based on manganese, ${ }^{12}$ ruthenium ${ }^{13}$ and cobalt oxides, ${ }^{14}$ including the active site of the

\footnotetext{
${ }^{a}$ Diamond Light Source, Harwell Science and Innovation Campus, Didcot OX11 ODE, UK. E-mail: stuart.bartlett@diamond.ac.uk

${ }^{b}$ Centre for Sustainable Chemical Technologies, University of Bath, Bath BA2 7AY, UK. E-mail: u.hintermair@bath.ac.uk

${ }^{c}$ School of Chemistry, University of Glasgow, Glasgow G12 8QQ, UK

${ }^{d}$ School of Chemistry, University of Southampton, Southampton SO17 1BJ, UK

${ }^{e}$ Paul Scherrer Institute, 5232 Villigen, Switzerland

${ }^{f}$ Catalytic Innovations, Fall River, MA, 02723, USA

$\dagger$ Electronic supplementary information (ESI) available: Details of XAS fitting analyses (XANES and EXAFS), structural details and additional plots. See DOI: $10.1039 / \mathrm{c} 9 \mathrm{cc} 02088 \mathrm{~h}$
}

natural oxygen-evolving complex (OEC) in photosystem II. $^{15}$ Over the past decade some highly active molecular Ir-based WOCs have been developed, ${ }^{16}$ though some have been shown to rapidly transform into $\mathrm{IrO}_{x}$ nanoparticles in situ. ${ }^{17}$ Strongly binding and oxidatively robust ligands (such as pyridinealkoxides ${ }^{18}$ ) however yield highly active WOC solutions that are fully homogeneous. ${ }^{19}$ After activation ${ }^{20}$ these can even be grafted onto conducting metal oxides as molecular monolayers to yield exceptionally efficient and durable anodes for electrochemical water oxidation. ${ }^{21-23}$ Although a number of spectroscopic features have been analyzed, ${ }^{24}$ the exact molecular structure of these highly active catalysts has not yet been elucidated. A previous study of a pyridine-alkoxide ligated Ir WOC using high-energy X-ray scattering (HEXS) analysis and density functional theory (DFT) modelling suggested a mono- $\mu$-oxo Ir dimer as the resting state of the activated catalyst, ${ }^{25}$ and in the following a series of coordinately saturated mono- $\mu$-oxo dimers with two pyalk ligands per iridium centre have been synthesised. ${ }^{26}$ These intriguing model compounds allowed the direct characterization of higher valent states not observable in the parent catalyst bearing one pyalk ligand per metal, but the question how relevant the mono- $\mu$ oxo motif to catalysis is remains. Here we present our results from a detailed X-ray absorption spectroscopy study of a molecular Ir-pyalk WOC in solution that provide strong evidence for bis- $\mu$ oxo units in dimeric and tetrameric species as the resting state of the catalyst.

XAS has been successfully employed in several cases to gain structural insight into functional WOCs, including the $\mathrm{CaMn}_{4}$ oxo-cubane OEC in PSII, ${ }^{27} \mathrm{CoO}_{x}$ films $^{14,28}$ and molecular Ru WOCs immobilized on surfaces. ${ }^{29}$ Here we investigated the activated form of [Cp* $\mathrm{Cr}$ (dimethyl-pyridinealkoxide)Cl] obtained by stirring with 50 equivalents of $\mathrm{NaIO}_{4}$ in water at room temperature for 16 hours (termed Ir-pyalk WOC), conditions which have previously been shown to yield a homogeneous iridium species without any bound $\mathrm{Cp}^{*}$ but retaining the pyalk ligand. ${ }^{19,24,30}$ XAS measurements were performed directly on freshly prepared $5 \mathrm{mM}$ aqueous solutions, and on cellulose pellets of the dark blue solid obtained after slow evaporation of 


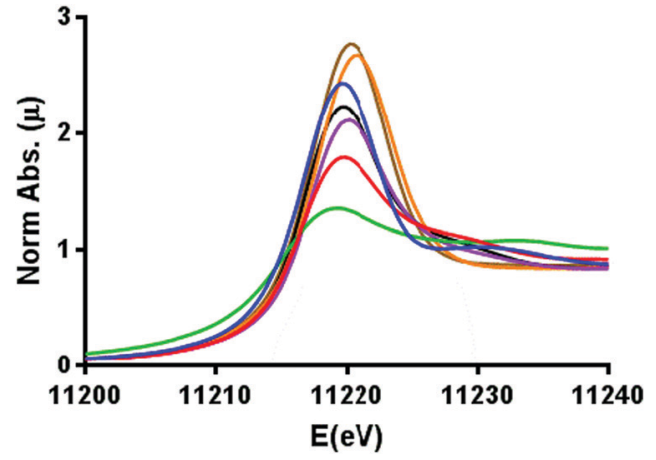

Fig. 1 Normalized XANES spectra calibrated to the $\mathrm{Pt}^{0} \mathrm{~L}_{3}$ edge, displaying

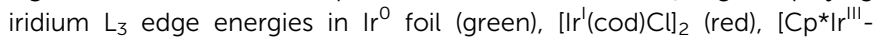
$\left.\left(\mathrm{H}_{2} \mathrm{O}\right)_{3}\right] \mathrm{SO}_{4}$ (purple), [Cp*Ir'(pyalk)Cl] (black), $\mathrm{Na}_{2}\left[\mathrm{lr}^{\mathrm{IV}} \mathrm{Cl}_{6}\right]$ (blue), $\mathrm{Ir}^{\mathrm{IV}} \mathrm{O}_{2}$ (orange), and the Ir-pyalk WOC (brown). For further details see Fig. S5 (ESI†).

these solutions to dryness (yielding identical spectra). Reference samples of $\operatorname{Ir}^{0}$ (metal foil), $\operatorname{Ir}^{\mathrm{I}}\left([\operatorname{Ir}(\text { cod }) \mathrm{Cl}]_{2}\right), \operatorname{Ir}^{\mathrm{III}}\left(\left[\mathrm{Cp}^{*} \operatorname{Ir}(\right.\right.$ pyalk)Cl $]$ and $\left.\left[\mathrm{Cp}^{*} \operatorname{Ir}\left(\mathrm{H}_{2} \mathrm{O}\right)_{3}\right] \mathrm{SO}_{4}\right)$, and $\mathrm{Ir}^{\mathrm{IV}}\left(\mathrm{Na}_{2}\left[\operatorname{IrCl}_{6}\right]\right.$ and $\left.\mathrm{IrO}_{2}\right)$ were measured as standards for the different metal oxidation states. The XAS data was collected at the SuperXAS beamline at the Swiss Light Source and B18 at the UK Diamond Light Source at the iridium $\mathrm{L}_{3}$ edge at 11$12.5 \mathrm{keV}$ in fluorescence mode.

The comparative XANES of the reference samples (Fig. 1) showed a general trend of increasing white line intensity with increasing oxidation states. This is expected due to the $\operatorname{Ir} \mathrm{L}_{3}$ edge X-ray absorption constituting an allowed $2 \mathrm{p} \rightarrow 5 \mathrm{~d}$ transition, where the intensity increases in higher oxidation states as more states become available in the $5 \mathrm{~d}$ orbitals, but shielding dampens the effective nuclear charge so that transition energies are not systematically affected by the oxidation state. ${ }^{31,32}$ The Ir-pyalk WOC sample in question having very similar XANES to that of $\mathrm{IrO}_{2}$ suggested the catalyst to rest in the $\mathrm{Ir}^{\mathrm{IV}}$ oxidation state, consistent with its characteristic blue color and previous XPS analysis. $^{24}$

Analysis of the extended X-ray absorption fine structure (EXAFS) however revealed distinct differences in their respective structures. Fig. 2 shows an overlay of the FT-EXAFS spectra of the $\mathrm{IrO}_{2}$ reference and the Ir-pyalk WOC sample, revealing a similar first coordination shell (blue shaded section) but major

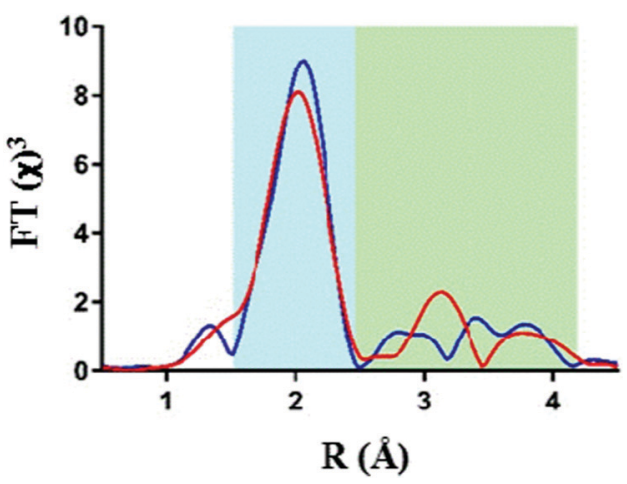

Fig. 2 Comparison of $\operatorname{Ir} L_{3}$ edge EXAFS data with $k^{3}$-weighting, showing Fourier transform EXAFS data for $\mathrm{IrO}_{2}$ (red) and the Ir-pyalk WOC (blue). differences in the longer-range order between the two samples (green shaded section).

The best fit parameters for the $\mathrm{IrO}_{2}$ EXAFS spectrum showed the first coordinating shell around $2 \AA$ to consist of six bridging oxygen atoms with a uniform Ir-O bond distance of $1.98 \AA$ (Table 1). The similarity of the first shell between $\mathrm{IrO}_{2}$ and Ir-pyalk WOC suggests a similar direct bonding environment to be present in the Ir-pyalk WOC sample (i.e., six low $\mathrm{Z}$ atoms around $2 \AA$ ). The analysis of peaks $>2.5 \AA$ of the $\mathrm{IrO}_{2}$ spectrum required defining each single contribution from the overlapping multiple backscattering pathways. These multiple scattering pathways are particularly prevalent in rigid, ordered structures such as crystalline metal oxides, but are known to be difficult to resolve for iridium due the absence of characteristic high amplitude peaks around $3 \AA$ in the Fourier transform. ${ }^{33} \mathrm{~A}$ comprehensive fitting analysis yielded optimum parameters indicating two neighboring Ir atoms at $3.11 \AA$ and eight Ir atoms at $3.52 \AA$ (Table 1, Table S1 and Fig. S2, ESI $\dagger$ ), fully consistent with XRD results. ${ }^{34}$

To fit and compare the FT EXAFS spectrum of the Ir-pyalk WOC three structural motifs were investigated: a flexible mono$\mu$-oxo dimer (1), ${ }^{25}$ a more rigid bis- $\mu$-oxo dimer (2), ${ }^{24}$ and a more extended "dimer of dimers" bis- $\mu$-oxo cubane (3) (Fig. 3 and Table 1).

The bis- $\mu$-oxo dimer structure 2 gave a high statistical fit for a short Ir-Ir distance of $2.97 \AA$ with two bridging oxygen atoms, distinctly shorter than the $3.11 \AA$ found in the "diamond core" of $\mathrm{IrO}_{2}$ by XAS (Table 1) and XRD. ${ }^{34}$ This contraction mainly originated from coordination of the chelating pyalk ligand, and not from a switch to $\mu^{2}-\mathrm{O}$ from $\mu^{3}-\mathrm{O}$ in $\mathrm{IrO}_{2}$ (see also discussion of 3 below). With the four terminal N/O ligands from the pyalk ligand and coordinated water molecules forming the second shell, a good statistical fit with an $R_{\text {fac }}$ (measure of fit accuracy, see ESI $\dagger$ ) of 0.006 was obtained for 2 (Fig. 4 and Table S2, ESI $\dagger$ ). All attempts to fit the flexible mono- $\mu$-oxo dimer $\mathbf{1}^{25}$ to our EXAFS data yielded much poorer statistical fits of $R_{\mathrm{fac}}=0.014$ or higher. This arises due to the inclusion of a substantially

Table 1 Best parameters obtained from fitting the $\operatorname{Ir} L_{3}$ edge EXAFS spectra of $\mathrm{IrO}_{2}$ and $\mathrm{Ir}$-pyalk WOC using structures 1-3 (brackets indicate a variable in the fitting; further details on the analysis including plots of all path contributions are given in Tables S1-S3, ESI). Literature values for $\mathbf{1}^{25}$ were used to fit the structure to our experimental data, where the path lengths and $\sigma^{2}$ values were fixed to the published distances

\begin{tabular}{lllll}
\hline Structure & Path & Distance $(\AA)$ & $\sigma^{2}\left(\AA^{2}\right)$ & $R_{\text {fac }}$ \\
\hline $\mathrm{IrO}_{2}$ & $6 \mathrm{Ir}-\mathrm{O}$ & $1.98(1)$ & $0.006(1)$ & 0.001 \\
& $2 \mathrm{Ir}-\mathrm{Ir}$ & $3.11(3)$ & $0.006(3)$ & \\
$\mathbf{1}$ & $8 \mathrm{Ir}-\mathrm{Ir}$ & $3.52(8)$ & $0.017(11)$ & \\
& $6 \mathrm{Ir}-\mathrm{O} / \mathrm{N}$ & 2.04 & 0.004 & 0.014 \\
& $2 \mathrm{Ir}-\mathrm{C}$ & 2.81 & 0.009 & \\
& $4 \mathrm{Ir}-\mathrm{C}$ & 2.97 & 0.006 & \\
2 & $1 \mathrm{Ir}-\mathrm{Ir}$ & 3.56 & 0.002 & \\
& $2 \mathrm{Ir}-\mathrm{O}$ & $1.96(1)$ & 0.002 & 0.006 \\
& $4 \mathrm{Ir}-\mathrm{O} / \mathrm{N}$ & $2.50(7)$ & $0.012(13)$ & \\
3 & $1 \mathrm{Ir}-\mathrm{Ir}$ & $2.97(4)$ & $0.002(3)$ & \\
& $3 \mathrm{Ir}-\mathrm{O}$ & $1.96(3)$ & $0.006(4)$ & 0.001 \\
& $3 \mathrm{Ir}-\mathrm{O} / \mathrm{N}$ & $2.04(3)$ & $0.001(1)$ & \\
& $3 \mathrm{Ir}-\mathrm{Ir}$ & $2.97(3)$ & $0.012(3)$ &
\end{tabular}




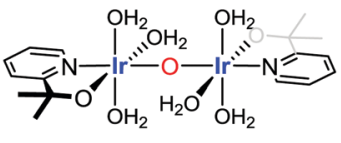

1

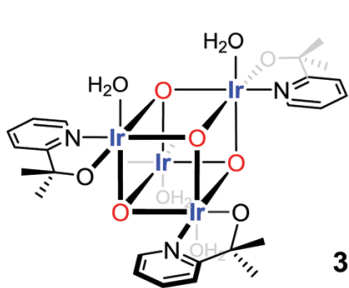

Fig. 3 Three structural motifs used in the EXAFS fitting analysis of the Ir-pyalk WOC derived from [C $\mathrm{p}^{*}$ Ir(dimethyl-pyridinealkoxide) $\mathrm{Cl}$ in dilute aqueous solution.
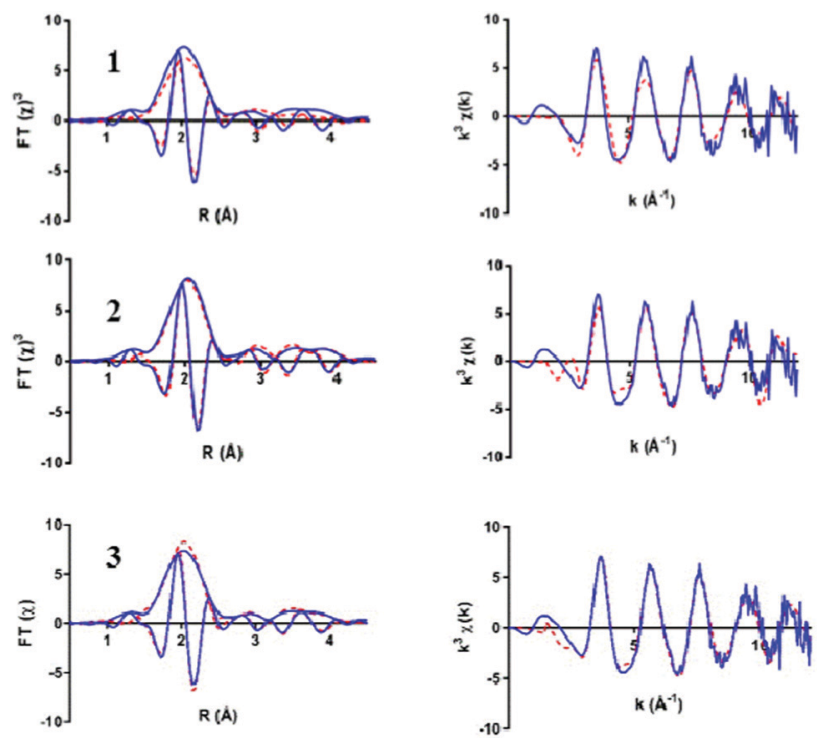

Fig. 4 Ir $L_{3}$ edge EXAFS spectra of the Ir-pyalk WOC in solution (blue) comparing three simulated fit models from Fig. 3 (red dashed): mono- $\mu^{2}-$ oxo dimer $\mathbf{1}$, bis- $\mu^{2}$-oxo dimer $\mathbf{2}$, and bis- $\mu^{3}$-oxo cubane $\mathbf{3}$. Displaying $k^{3}$ weighted Fourier Transform (with imaginary part, left) and $k^{3}$ weighted EXAFS plot (right) for each structure.

increased Ir-Ir distance of 3.56 A originating from the mono- $\mu$ oxo unit. We found this to be incompatible with our EXAFS data showing that the Ir-Ir distance must be less than $3 \AA$, which cannot be obtained with a single oxo bridge between the metals. ${ }^{35}$

On the other hand, the even more rigid cubane structure 3 with three Ir contributions maintained the same Ir-Ir distance as found in 2, with the remaining three $\mathrm{N} / \mathrm{O}$ ligands moving to a shorter distance of 2.06(2) ̊ (Table S3 (ESI $\dagger$ ) and Fig. 4). This arrangement provided an even better fit with a global $R_{\mathrm{fac}}$ of 0.001, showing excellent agreement with the EXAFS data out to $k$ ranges beyond $10 \AA^{-1}$ (Fig. 4).

Inspecting the individual pathway contributions in the best fit analysis between structure 3 and 2 , only in the cubane structure 3 did the higher Ir coordination number adequately fit the shoulder peak contribution at $3.0 \AA$ in the imaginary part of the Fourier Transform (Fig. S6, ESI $\dagger$ ). In the dimer model 2 the Ir-Ir shell cannot fully reproduce this peak, requiring a shift to higher distance for the ligands to compensate, thus degrading the overall fit (Fig. S6, ESI $\dagger$ ). This is indication that a nuclearity greater than two is present in the majority of the sample, with the best fitting analysis suggesting a neighboring iridium number of three as in the cubane structure 3. Indeed, setting the Ir-Ir coordination number as a floating variable, the fitting optimization converged to an average of 2.6(4) neighboring Ir atoms. In addition, literature XRD data ${ }^{36}$ are in good agreement with the $\operatorname{Ir}^{\mathrm{IV}}-\mathrm{N} / \mathrm{O}$ distances of $2.05 \AA$ found in 3 .

Comparing structures 2 and 3 , the cubane differs in the reduction of terminal ligand sites from four to three, a shortening of Ir-N/O distances from $2.51 \AA$ to $2.04 \AA$, and an increase of neighboring Ir atoms from one to three in the tetranuclear oxo-cubane. This provided a superior statistical fit with realistic bond distances for structure 3 even compared to the good fit for structure 2. This analysis shows both bis- $\mu$-oxo dimers and tetramers to be viable possibilities, with the EXAFS fit indicating an oxo-cubane type 'dimer-of-dimer' structure 3 to be the most realistic structural representation of the resting state of the activated Ir-pyalk WOC in aqueous solution.

We have provided a detailed structural analysis of a prominent molecular WOC through iridium $\mathrm{L}_{3}$ edge XAS. The results find mono- $\mu$-oxo linkages to allow too much flexibility and induce too large Ir-Ir distances to be compatible with experimental EXAFS data of the resting state of the activated catalyst, suggesting that such species may not be relevant to water oxidation catalysis. ${ }^{35}$ Our analysis points to more compact and rigid bis- $\mu$-oxo linkages in oxo-cubane 'dimer-of-dimers' as the key structural feature in these highly active and durable WOCs. Similar metal-oxo cubanes have been shown to feature in a number of WOCs based on other transition metals such as $\mathrm{Mn}, \mathrm{Co}$, and $\mathrm{Ni}$ (including the natural OEC in PSII), ${ }^{27,37}$ and their unique robustness and redox chemistry may represent a common design criterion allowing for high activity and stability in the demanding 4-electron oxidation of water. Importantly, a pyalk-modified bis- $\mu$-oxo $\operatorname{Ir}_{4} \mathrm{O}_{4}$ cubane would be consistent with previously reported characterization data including ${ }^{17} \mathrm{O}$ NMR, EPR, UV-vis and resonance-Raman spectroscopies, ${ }^{24}$ and shed new light on the mode of surface binding of these catalysts. ${ }^{38-40}$ However, we caution that the kinetic role of such tetrameric resting states will have to be clarified prior to mechanistic interpretations. Recently a half order in [Ir] on the rate of $\mathrm{O}_{2}$ evolution has been found for a range of pyalkligated Ir WOCs using $\mathrm{NaIO}_{4}$, implying a dominant dimeric resting state liberating small amounts of active monomer into the catalytic cycle. ${ }^{41}$ In light of the present findings this could mean a tetramer-dimer, or tetramer-dimer-monomer equilibria to be operational instead. Ascertaining how many metal sites are involved in the turnover-limiting step will be important for deciphering the workings of these highly active catalysts.

This work was supported by the Royal Society (UF160458; University Research Fellowship to UH), the EPSRC Centre for Doctoral Training in Sustainable Chemical Technologies (EP/L016354/1; PhD studentship to EVS), and the UK Catalysis 
Hub (EP/K014714/1). The authors acknowledge the Diamond Light Source for provision of beamtime (SP10306 and SP15151). The authors would like to thank Mark Styles and Nathan Webster (CSIRO, Australia), Robert Potter (Johnson Matthey), and Paul Frith (University of Bath) for their support and assistance with this project.

\section{Conflicts of interest}

US Patent No. 9,790,605 by SWS, UH et al. contains intellectual property described in this article. The other authors declare no competing financial interest.

\section{Notes and references}

1 A. Nicola and B. Vincenzo, Angew. Chem., Int. Ed., 2007, 46(1-2), 52.

2 I. Katsounaros, S. Cherevko, A. R. Zeradjanin and K. J. Mayrhofer, Angew. Chem., Int. Ed., 2014, 53(1), 102.

3 M. D. Kärkäs, O. Verho, E. V. Johnston and B. Åkermark, Chem. Rev., 2014, 114(24), 11863.

4 J. D. Blakemore, R. H. Crabtree and G. W. Brudvig, Chem. Rev., 2015, 115(23), 12974.

5 C. C. L. McCrory, S. Jung, J. C. Peters and T. F. Jaramillo, J. Am. Chem. Soc., 2013, 135(45), 16977.

6 P. Steegstra, M. Busch, I. Panas and E. Ahlberg, J. Phys. Chem. C, 2013, 117(40), 20975.

7 A. Minguzzi, C. Locatelli, O. Lugaresi, E. Achilli, G. Cappelletti, M. Scavini, M. Coduri, P. Masala, B. Sacchi, A. Vertova, P. Ghigna and S. Rondinini, ACS Catal., 2015, 5(9), 5104.

8 A. Minguzzi, O. Lugaresi, E. Achilli, C. Locatelli, A. Vertova, P. Ghigna and S. Rondinini, Chem. Sci., 2014, 5(9), 3591.

9 H. G. S. Casalongue, M. L. Ng, S. Kaya, D. Friebel, H. Ogasawara and A. Nilsson, Angew. Chem., Int. Ed., 2014, 53(28), 7169.

10 V. Pfeifer, T. E. Jones, S. Wrabetz, C. Massué, J. J. Velasco Vélez, R. Arrigo, M. Scherzer, S. Piccinin, M. Hävecker, A. Knop-Gericke and R. Schlögl, Chem. Sci., 2016, 7(11), 6791.

11 H. Ooka, Y. Wang, A. Yamaguchi, M. Hatakeyama, S. Nakamura, K. Hashimoto and R. Nakamura, Phys. Chem. Chem. Phys., 2016, 18(22), 15199.

12 A. Bergmann, I. Zaharieva, H. Dau and P. Strasser, Energy Environ. Sci., 2013, 6(9), 2745.

13 H. Over, Chem. Rev., 2012, 112(6), 3356.

14 M. Risch, V. Khare, I. Zaharieva, L. Gerencser, P. Chernev and H. Dau, J. Am. Chem. Soc., 2009, 131(20), 6936.

15 J. McEvoy and G. W. Brudvig, Chem. Rev., 2006, 106(11), 4455.

16 J. M. Thomsen, D. L. Huang, R. H. Crabtree and G. W. Brudvig, Dalton Trans., 2015, 44(28), 12452.

17 V. Artero and M. Fontecave, Chem. Soc. Rev., 2013, 42(6), 2338.

18 T. K. Michaelos, D. Y. Shopov, S. B. Sinha, L. S. Sharninghausen, K. J. Fisher, H. M. C. Lant, R. H. Crabtree and G. W. Brudvig, Acc. Chem. Res., 2017, 50(4), 952.

19 U. Hintermair, S. M. Hashmi, M. Elimelech and R. H. Crabtree, J. Am. Chem. Soc., 2012, 134(23), 9785.
20 J. M. Thomsen, S. W. Sheehan, S. M. Hashmi, J. Campos, U. Hintermair, R. H. Crabtree and G. W. Brudvig, J. Am. Chem. Soc., 2014, 136(39), 13826.

21 S. W. Sheehan, J. Thomsen, U. Hintermair, R. H. Crabtree, G. W. Brudvig and C. A. Schmuttenmaer, Nat. Commun., 2015, 6, 6469.

22 W. Li, S. W. Sheehan, D. He, Y. He, X. Yao, R. L. Grimm, G. W. Brudvig and D. Wang, Angew. Chem., Int. Ed., 2015, 54, 11428.

23 J. W. Moir, E. V. Sackville, U. Hintermair and G. A. Ozin, J. Phys. Chem. C, 2016, 120(24), 12999.

24 U. Hintermair, S. W. Sheehan, A. R. Parent, D. H. Ess, D. T. Richens, P. H. Vaccaro, G. W. Brudvig and R. H. Crabtree, J. Am. Chem. Soc., 2013, 135(29), 10837.

25 K. R. Yang, A. J. Matula, G. Kwon, J. Hong, S. W. Sheehan, J. M. Thomsen, G. W. Brudvig, R. H. Crabtree, D. M. Tiede, L. X. Chen and V. S. Batista, J. Am. Chem. Soc., 2016, 138(17), 5511.

26 L. S. Sharninghausen, S. B. Sinha, D. Y. Shopov, B. Choi, B. Q. Mercado, X. Roy, D. Balcells, G. W. Brudvig and R. H. Crabtree, J. Am. Chem. Soc., 2016, 138(49), 15917.

27 J. Yano, J. Kern, K. Sauer, M. J. Latimer, Y. Pushkar, J. Biesiadka, B. Loll, W. Saenger, J. Messinger, A. Zouni and V. K. Yachandra, Science, 2006, 314(5800), 821.

28 X. Li, E. B. Clatworthy, S. A. Bartlett, A. F. Masters and T. Maschmeyer, J. Phys. Chem. C, 2017, 121(21), 11021.

29 D. Lebedev, Y. Pineda-Galvan, Y. Tokimaru, A. Fedorov, N. Kaeffer, C. Copéret and Y. Pushkar, J. Am. Chem. Soc., 2018, 140(1), 451.

30 E. V. Sackville, G. Kociok-Köhn and U. Hintermair, Organometallics, 2017, 36(18), 3578.

31 A. Uzan and B. C. Gates, Angew. Chem., Int. Ed., 2008, 47(48), 9245.

32 J. H. Choy, K. Dong-Kuk, G. Demazeau and D. Y. Jung, J. Phys. Chem., 1994, 98, 6258.

33 E. Prouzet, J. Phys.: Condens. Matter, 1995, 7, 8027.

34 A. A. Bolzan, C. Fong, B. J. Kennedy and C. J. Howard, Acta Crystallogr., Sect. B: Struct. Sci., 1997, 53, 373.

35 A possible explanation for previous findings of Ir-Ir distances of $\sim 3.5 \AA$, leading to the proposal of mono- $\mu$-oxo structures, could be the fact samples had been prepared at much higher Ir concentrations in advance of the analysis. This may have led to the formation of $\mathrm{IrO}_{2}$ particles that give Ir-Ir backscattering peaks in exactly that region (see Table 1), which we did not observe in homogeneous samples freshly prepared below the critical Ir concentration of $10 \mathrm{mM}$.

36 S. B. Sinha, D. Y. Shopov, L. S. Sharninghausen, C. J. Stein, B. Q. Mercado, D. Balcells, T. Pedersen, M. Reiher, G. W. Brudvig and R. H. Crabtree, J. Am. Chem. Soc., 2017, 139, 9672.

37 F. Song, R. Moré, M. Schilling, G. Smolentsev, N. Azzaroli, T. Fox, S. Luber and G. R. Patzke, J. Am. Chem. Soc., 2017, 139(40), 14198.

38 Y. Zhao, K. R. Yang, Z. Wang, X. Yan, S. Cao, Y. Ye, Q. Dong, X. Zhang, J. E. Thorne, L. Jin, K. L. Materna, A. Trimpalis, H. Bai, S. C. Fakra, X. Zhong, P. Wang, X. Pan, J. Guo, M. Flytzani-Stephanopoulos, G. W. Brudvig, V. S. Batista and D. Wang, Proc. Natl. Acad. Sci. U. S. A., 2018, 115(12), 2902.

39 Y. Zhao, X. Yan, K. R. Yang, S. Cao, Q. Dong, J. E. Thorne, K. L. Materna, S. Zhu, X. Pan, M. Flytzani-Stephanopoulos, G. W. Brudvig, V. S. Batista and D. Wang, ACS Cent. Sci., 2018, 4(9), 1166.

40 I. Poli, U. Hintermair, M. Regue, S. Kumar, E. V. Sackville, J. Baker, T. M. Watson, S. Eslava and P. J. Cameron, Nat. Commun., 2019, 10, 2097.

41 E. V. Sackville, F. Marken and U. Hintermair, ChemCatChem, 2018, 10(19), 4280. 